\title{
LA NOCIÓN DE SUJETO EN EDUCACIÓN: APORTES PARA REPENSAR LA PRÁCTICA DOCENTE.
}

Prof. Stefanía Conde Irigaray.

\begin{abstract}
"La educabilidad es tolerable si se articula al reconocimiento de un no-poder radical sobre el sujeto en su acto de conocer. La opacidad de la consistencia y la imprevisibilidad del deseo vuelven imposible toda tentativa de dirigir el acto de aprender" P. Meirieu.
\end{abstract}

\section{Objetivo}

En el presente trabajo se propone pensar la práctica docente en torno a la noción de sujeto que subyace en educación. En el marco de un sistema educativo estructurado en función de lógicas de normalización con pretensión de homogeneidad que dan lugar a una concepción de sujeto posible de gobernar, irrumpe la noción de sujeto escindido, dividido por la conciencia y el inconsciente; un sujeto faltante, deseante, que hace del educar -siguiendo a Freud- una de las profesiones imposibles.

La pregunta que guiará el análisis será: ¿qué repercusiones tienen una y otra concepción de sujeto al momento de pensar la enseñanza y el aprendizaje?

\section{Justificación}

$\mathrm{Si}$ entendemos por educación todo aquello que conforma lo humano, cuestionarnos acerca de la concepción de sujeto constituye un asunto fundamental. Es desde esta concepción que nos posicionaremos como enseñantes, incidiendo ella en nuestro accionar.

Considerando que aún en la actualidad las lógicas de la escuela nos siguen remitiendo a ciertos planteos que Foucault realizara en su conocida obra "Vigilar y Castigar", evidenciar dichas lógicas y por consiguiente la noción de sujeto que se constituye desde ese lugar, será un paso importante para emancipar la mirada, pensando a partir de allí otra concepción de sujeto y por consiguiente, otra forma de entender la enseñanza. 
Teniendo presente que para pensar en formas de subjetivación de nuestros estudiantes, primero debemos procurar formas de subjetivación propias, el presente análisis se erige como una oportunidad para repensar nuestra práctica con la finalidad de promover la emancipación en nosotros mismos.

\section{Asunto}

La escuela se esfuerza para que todos se sometan a un mismo modelo, intenta normalizar y por lo tanto homogeneizar. De este modo, la particularidad del sujeto queda subsumida a una pretensión igualitaria.

En este marco, ciertas lógicas expuestas por Foucault en "Vigilar y castigar" continúan hoy vigentes en el sistema educativo: control del tiempo, vigilancia jerárquica, sanción normalizadora, distribución de los estudiantes según rangos, el examen como "ritual de poder" que clasifica y jerarquiza. Es posible afirmar que a través de los denominados "medios del buen encauzamiento", la educación se empeña en regular al otro, controlándolo por medio de patrones de normalización que persiguen la homogeneización. Siguiendo al autor, tiene lugar en la institución escolar "... una presión constante para que se sometan todos al mismo modelo (...) para que todos se asemejen" (Foucault, 2002: 169).

Siguiendo a Dubet, la escuela reposa sobre la homogeneidad de la oferta escolar, procurando así garantizar la igualdad. Una igualdad que si bien no es real ni empírica sino ontológica, permite convertir a la escuela en un santuario, en el entendido de que lo que se desarrolla allí no pertenece al orden habitual de las relaciones sociales. De este modo, la escuela está fuera del mundo, es moralmente cohesiva, es un santuario al abrigo de las divisiones de la vida social; allí todo permanece extrasocial, ya que se sitúa por encima de la diversidad de los grupos y clases. En el corazón de las políticas escolares, se entiende que la homogeneización que garantiza la "igualdad" es la manera más eficaz de lograr la integración social.

En el marco de estas lógicas del sistema escolar, es que se va conformando una noción de sujeto que repercute directamente en la enseñanza y en el aprendizaje, presentándose, desde este lugar, como procesos totalmente controlables. Más aún, existe “... la convicción de que tanto la educación como 
la enseñanza se asientan en la posibilidad de completar, desarrollar y transformar plenamente al sujeto" (Bordoli, 2011: 96).

A decir de Foucault, todo aquello que no se ajusta a la regla constituye una desviación, siendo la "falta" del alumno una ineptitud para cumplir sus tareas. En esta línea de análisis, es posible observar en la actualidad que cuando un estudiante no aprende, se pretende explicarlo, o bien desde discursos del propio campo educativo, vinculados a cambios curriculares, generación de nuevos espacios y nuevos roles; o bien desde aquellos provenientes del campo sociológico, de modo que los aprendizajes se explican por factores externos al sujeto, tales como la procedencia social.

En la propia práctica de enseñanza, la idea que subyace es la de un sujeto susceptible de aprender con ciertas estrategias o métodos en un tiempo determinado. La idea no es otra que la de un sujeto posible de gobernar, con la consiguiente afirmación de que lo enseñado se corresponde con lo aprendido. A decir de Foucault en su obra antes mencionada, "... la duración de un aprendizaje, el tiempo de un ejercicio, el nivel de aptitud, se refieren a una regularidad, que es también una regla" (Foucault, 2002: 166).

En este marco, la formación pedagógica hace creer al docente en la posibilidad de controlar totalmente los procesos de aprendizaje, cree posible una transmisión neutral, sin implicación subjetiva.

Se desconoce que lo que se aprende es diferente de lo que se enseña. Lo que opera es la "ficción pedagógica" consistente en un "como si": como si se enseñara por parte del docente y como si se aprendiera por parte de los alumnos. Más aún, hay una certeza, una ilusión: que el tiempo legal de la enseñanza se corresponde con el tiempo del aprendizaje. Existe la creencia de que es posible anticipar lo que será la futura modalidad de vínculo de cada sujeto con un saber, subsumiéndolo a las lógicas del tiempo legal de la enseñanza que presenta al saber como saber general y no como producto de una labor subjetiva, y por lo tanto, único en cada sujeto. A decir de Chevallard, "Frente a este tiempo que se le impone, el sujeto didáctico postula su subjetividad y su "historia" personal; es interpelado y debe, en cierto sentido, responder según la estructura de una temporalidad subjetiva particular que se 
define en el marco del tiempo de la enseñanza, sin identificarse de todos modos con éste" (Chevallard, 1991: 80).

Este tiempo legal de la enseñanza constituye una ficción que desde el punto de vista funcional y aunque el tiempo del aprendizaje se anteponga, se torna necesaria: “... el tiempo didáctico legal, el tiempo de la enseñanza aparece como una ficción que prohíbe desvíos en la duración, tanto si se trata de avances como de retrasos. Esta instancia designa una norma dinámica que define el ritmo del avance didáctico y en la relación con la cual, como ocurre con toda norma, los desvíos (temporales) son percibidos como simples faltas (retrasos) o son, más radicalmente, escotomizados" (Chevallard, 1991: 97).

Esta conceptualización del tiempo legal de la enseñanza (el tiempo que se programa desde la didáctica) y tiempo del aprendizaje (la adquisición del saber) se vincula con las nociones de tiempo cronológico y tiempo lógico de Lacan. A decir de Ana María Fernández (2008: 108), para que se produzca el aprendizaje se requiere que el saber enseñado interpele al sujeto desde un tiempo lógico, inscripto por lo tanto en una dimensión subjetiva.

Según Lacan, podemos distinguir en el tiempo lógico tres momentos: el instante de la mirada (el cual tiene lugar a partir de lo que se le presenta al sujeto a simple vista, siendo un proceso casi instantáneo), el tiempo para comprender (tiempo en que el sujeto busca determinar su posición frente al otro) y el momento de concluir, producto de los dos anteriores.

Estas tres fases repercuten en nuestra posición como enseñantes, en la medida que se torna importante pensar nuestra actividad a través de la mirada del pequeño otro (instante de la mirada); tratar de entender lo que estamos haciendo a partir de los vínculos que entablamos con nuestros estudiantes (tiempo de comprender), procurando lograr una mirada de nosotros mismos que nos habilite a regular nuestro accionar (tiempo de concluir).

De este modo, el tiempo lógico irrumpe contra el concepto de enseñanza que subyace en nuestra práctica docente: una concepción de la enseñanza que se presenta desde una visión instrumental poniendo énfasis en el método, concibiéndose como acto, en tanto acción que el enseñante ejerce sobre el 
enseñado con la posibilidad de controlar -en este caso mediante el método- los efectos que el saber va produciendo en los sujetos.

En este marco, la ilusión de controlar los efectos de la enseñanza se encuentra interpelada por una realidad: la imposibilidad de gobernar totalmente al sujeto, producto de una dimensión subjetiva que escapa a cualquier control. Esta temporalidad subjetiva, este "tiempo del aprendizaje", nos traslada así a otra concepción de sujeto. Una noción de sujeto del inconsciente que hace de nuestra actividad una profesión imposible. Tal como lo plantea Freud en su obra "Análisis terminable e interminable" (1937): "Detengámonos un momento para asegurar al analista nuestra simpatía sincera por tener que cumplir él con tan difíciles requisitos en el ejercicio de su actividad. $Y$ hasta pareciera que analizar sería la tercera de aquellas profesiones "imposibles" en que se puede dar anticipadamente por cierta la insuficiencia del resultado. Las otras dos, ya de antiguo consabidas, son el educar y el gobernar".

Educar se torna profesión imposible porque no todo es gobernable o sujetable, pues siempre hay algo del sujeto que se sale de la estructura, de lo que está programado o prediseñado a priori de emprender la acción educativa. La enseñanza deja de ser controlable en la medida que se encuentra con el deseo, un deseo que se resiste a ser homogeneizado. En este sentido no todo es sujetamiento sino que hay subjetividad.

Desde este lugar es que podemos concebir que todo aprendizaje supone una decisión personal irreductible del que aprende, de modo que no hay posibilidad de controlar los efectos de la enseñanza. Más allá del método, adquiere relevancia el deseo de aprender; detrás de cada método hay una relación humana en la que docente y estudiante se afectan recíprocamente.

En este sentido, la ilusión de que todo puede ser regulado se opone así al reconocimiento de una particularidad que no puede / se resiste a ser normalizada. Esta resistencia nos lleva a plantear la relación entre el sujeto y sus pulsiones y la cultura, pues si la educación se torna profesión imposible, lo es también por los obstáculos que las pulsiones puedan oponer a la tarea civilizadora. Como señala Behares en "Enseñar en cuerpo y alma: la teoría de la enseñanza y el saber en la pulsión" (2007), por un lado, el niño se enfrenta a 
las necesidades egoístas de su pulsión, y, por otro, a las respuestas insuficientes y a las inhibiciones provenientes del mundo adulto, lo cual lo lleva a vivir en un malestar constante.

De esta forma, en "El malestar en la cultura" (1930), Freud plantea que una de las características de la organización de la sociedad humana es ser productora de malestar. La civilización se apoya en la renuncia pulsional que supone la no satisfacción, la postergación o la represión de las pulsiones: "La satisfacción de los instintos, precisamente porque implica tal felicidad, se convierte en causa de intenso sufrimiento cuando el mundo exterior nos priva de ella, negándonos la satisfacción de nuestras necesidades (...) la cultura reposa sobre la renuncia a las satisfacciones instintuales" (Freud, 1930: 78). Así, el desarrollo cultural implica la renuncia de satisfacciones como consecuencia del temor a la autoridad exterior.

Esta conceptualización de Freud adquiere relevancia en nuestro análisis en la medida en que para quien se halla en la posición de enseñante, el niño debe ser educado, lo cual implica que debe someterse a las reglas de la vida social, dominando sus pulsiones para convertirse en un ser humano respetable desde el punto de vista de la cultura.

En esta marco, la educación tiene una función civilizadora dado que intenta regular lo pulsional, pero al mismo tiempo deberá cuidar que la particularidad del sujeto no se vea ahogada por la presión homogeneizadora. En este sentido, si la educación tiene que hallar su punto medio, tiene que asumir antes que nada su carácter imposible, esto es, reconocer que siempre va a estar marcada por la presencia de objetivos inacabados.

Ahora bien, la función educativa debe saber operar con su carácter imposible, soportando siempre un límite, considerando que si el sujeto no renuncia a ciertas satisfacciones inmediatas, no puede aprender. A decir de Behares, para el niño, el saber se constituye en el lugar de su falta y de su demanda insatisfecha. En este sentido, como señala Lya Tourn, “... que las respuestas del adulto sean obligatoriamente insatisfactorias para el niño y que esto lo confronte a una experiencia en cierto grado "deprimente" no debe hacer olvidar que este "fracaso", esta insatisfacción y esta "depresión" son también 
pasos necesarios en su construcción como sujeto separado y... faltante. O sea, deseante, porque ¿cómo sería posible el deseo sin la falta?” (Tourn, 2009: 11).

Siguiendo a Behares, la falta de gozar y la falta de saber son para el sujeto la misma falta: una falta en el orden pulsional: "El saber, prohibido e insatisfactorio, que el niño "desea" porque le falta, es del orden pulsional" (Behares, 2007: 9). En este marco, es fundamental esa experiencia de falta para que se produzca algún movimiento.

Desde el campo de la educación se parte de la idea de que el maestro tiene el saber que al otro le falta. A decir de Ana María Fernández, "La diferencia radical entre la educación y el psicoanálisis consiste en que, en la primera, implica tomar en la transferencia el lugar del ideal del yo; y en el segundo, ubicarse en el lugar de no-saber (la posición del analista debe aproximarse a la posición de la docta ignorancia) y la producción del saber siempre es a posteriori (posterioridad)" (Fernández, 2005: 44). En este sentido se puede señalar que el analista no transmite un saber, pues el mismo se encuentra en el discurso del propio analizado.

Es en el marco de esta línea de análisis lacaniana que me gustaría pensar siguiendo el planteo que venimos realizando- en qué medida el docente puede salirse de ese lugar del "ideal del yo", escapando de alguna forma a la función normalizadora en la que se inscribe su rol, posicionándose desde el lugar de un no saber, que, pese a la situación de incomodidad, le permita abrirse al encuentro con el otro. Me pregunto si será posible salirnos del campo prescriptivo, de imposición de metas e ideales, para hacer emerger el deseo; pues siguiendo a Bordoli, “... más allá de los roles prescriptos en cada circunstancia particular, los sujetos nos encontramos en la misma posición de imposibilidad de ser en plenitud y de no saber en forma plena (...) Esto implica reconocer al otro en su singularidad y relativizar las clasificaciones particulares que se han extendido en el campo social y educativo y que generalmente cumplen un efecto estigmatizante sobre el otro" (Bordoli, 2011: 103).

Desde este lugar, teniendo presente que nosotros mismos somos seres incompletos, deberíamos dejar de anteponer nuestro saber al de los estudiantes, siendo necesario desarrollar una actitud de escucha que nos 
permita a partir de allí construir teoría a partir de sus propios saberes, impidiendo así que las normas queden antepuestas al sujeto.

\section{Conclusiones}

Desde el dispositivo escolar, y por consiguiente desde el rol docente, se espera controlar al sujeto, aproximándonos de esta forma a la noción de sujetamiento en detrimento de la subjetividad.

Las lógicas del sistema educativo parecen ahogar la idea de la imposibilidad de educar. La creencia de controlar los efectos del saber cobra insistencia en cualquier proyecto o política educativa: un control que normaliza en búsqueda de la igualdad. Una igualdad no empírica sino ontológica, concebida en términos de homogeneización, teniendo en cuenta que a través de la socialización la escuela pretende que se sometan todos a un mismo modelo.

En este marco, ya hemos visto que esta tarea es irrealizable. Asumir / recuperar la dimensión subjetiva atenta contra toda pretensión de control, contra cualquier aspiración igualitaria. He aquí la primera consecuencia que comporta para el rol docente la afirmación de Freud concerniente a la imposibilidad del educar: la imposibilidad de controlar los efectos que el saber va produciendo en los sujetos. A decir de Ana María Fernández, el saber, producto de una labor subjetiva, y por lo tanto saber particular se resiste a la homogeneidad, pues "El amor impide la generalización" (Fernández, 2011: 119).

No obstante, quizás la consecuencia más importante de esta situación sea la de convocarnos a repensar nuestra práctica y nuestro actuar como docentes, y a partir de allí encontrar los vestigios que nos permitan abrir un lugar para el sujeto, recuperando la dimensión del deseo.

Desde este lugar, y haciendo alusión a la estructura triádica del tiempo lógico establecida por Lacan, debemos pensar nuestra actividad como enseñantes a través de la mirada del pequeño otro (instante de la mirada); tratar de entender lo que estamos haciendo a partir de los vínculos que entablamos con nuestros estudiantes (tiempo de comprender), procurando 
lograr una mirada de nosotros mismos que nos habilite a regular nuestro accionar (tiempo de concluir).

Reconociendo la propia naturaleza del ser humano de carácter social y singular a la vez; concibiendo a la educación en su doble proceso de socialización y subjetivación, algunas interrogantes quedan planteadas:

- ¿de qué forma podremos salirnos del marco que las lógicas educativas nos imponen y buscar intersticios que den lugar a formas de subjetivación?

- ¿cómo trabajar desde la escuela con la heterogeneidad de las formas de saber?

Las interrogantes quedan abiertas y el desafío planteado, debiendo tener presente que será sin duda "Una enseñanza significada más por el desconcierto que por la certeza" (Fernández, 2011: 119), pues el aprendizaje mediado por el deseo, el encuentro entre el deseo y un contenido intelectual, impide cualquier pretensión de anticipación.

Palabras clave: SUJETO - ENSEÑANZA - APRENDIZAJE - DESEO

\section{Referencias bibliográficas}

Behares, L. (2007) "Enseñar en cuerpo y alma: la teoría de la enseñanza y el saber en la pulsión”. En: Cuerpo, Lenguaje y Enseñanza (2007). Educación Temática Digital, Campinas: 1-21.

Bordoli, E. (2011) "Reflexiones en torno a la enseñanza. Notas mínimas". En Behares, L. (2011) (Dir.): Didáskomai. Revista de Investigación sobre la Enseñanza. F.H.C.E, Montevideo: 93-105.

Chevallard, Y. (1991) La transposición didáctica. Del saber sabio al saber enseñado. Ed. Aique, Buenos Aires.

Dubet, F. (2006) El declive de la institución. Ed. Gedisa, Barcelona. 
Fernández, A.M. (2005) “¿Qué de la transferencia en el acontecimiento didáctico? Amor y saber en la imparidad subjetiva”. En Behares, L., Colombo, S. (2005) (Comp.): Enseñanza del Saber - Saber de la enseñanza. F.H.C.E, Montevideo: 37-45.

Fernández, A.M. y Rodríguez, R. (2011) "Reseña: Evocar la falta. La angustia y el deseo del enseñante". En Behares, L. (2011) (Dir.): Didáskomai. Revista de Investigación sobre la Enseñanza. F.H.C.E, Montevideo: 117-120.

Fernández, A.M. (2008) "Un estudio sobre el lugar del saber científico y el saber enseñado en la Didáctica”. En Behares, L. (2008) (Dir.): Didáctica Mínima. Los Acontecimientos del Saber. Psicolibros, Montevideo: 85-121.

Foucault, M. (2002) Vigilar y castigar. Ed. Siglo veintiuno, Buenos Aires.

Freud, S. (1930 [1929]) "El malestar en la cultura". En: Strachey, J. (2007): Sigmund Freud Obras Completas. Vol. 21, Ed. Amorrortu, Buenos Aires: 57140.

Freud, S. (1937) "Análisis terminable e interminable". En: Strachey, J. (1986): Sigmund Freud Obras Completas. Vol. 23. Ed. Amorrortu, Buenos Aires: 211254.

Lacan, J. (1945) "El tiempo lógico y el aserto de certidumbre anticipada. Un nuevo sofisma" En: Lacan, J. (1987): Escritos I. Siglo XXI, Buenos Aires: 187203.

Tourn, L. (2009) Epistemofilia, amor del saber y pasión de la ignorancia. Societé de psychabalyse freudienne (SPF), París. 